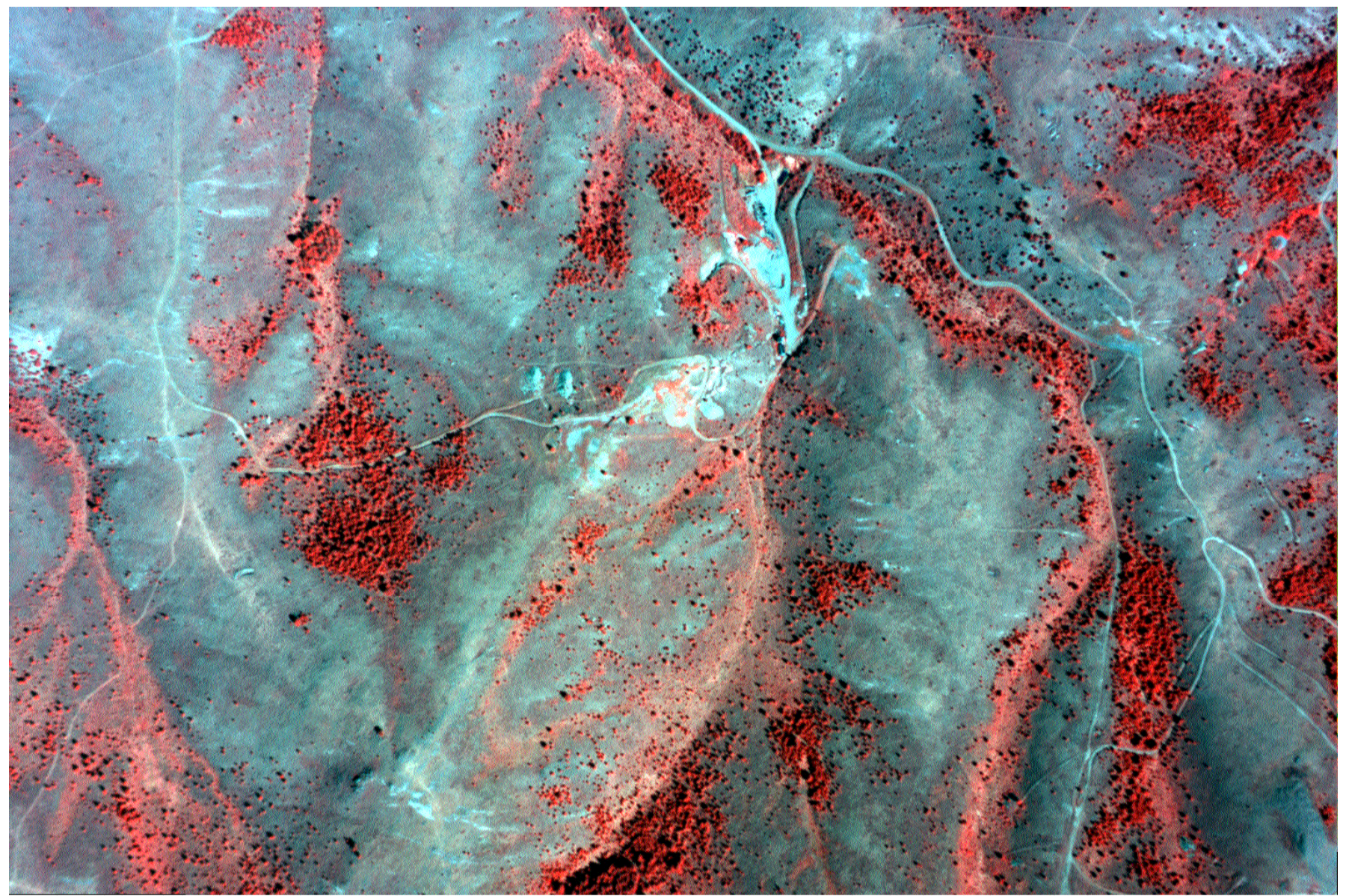

\title{
Guarding Against Invaders: Remote Sensing on the Range
}

\author{
By Evelyn Boswell
}

$\mathrm{M}$ ore than a dozen companies and government organizations joined forces this summer in Montana to try out new weapons in the battle against noxious weeds. "This is Big country," says Bill Tate, a Montanan of 65 years. "Problems like noxious weeds can beat you if you're not all over them."

Tate serves on the Ruby Watershed Council and spends summers fighting weeds on media executive and local rancher, Ted Turner's Snowcrest Ranch. By all accounts, he is doing what he can to battle the weeds around him. He is alarmed, though, by the leafy spurge and spotted knapweed that invade the Ruby River drainage and gobble up the native range. "What we need is a tool that can help us look beyond our own fences and set priorities as a community," Tate said. "Is remote sensing that tool?"

To help find a solution, Tate is participating in a unique experiment to see if aerial images can accurately map leafy spurge and spotted knapweed. Distinctive for its scope and sample size, the $\$ 250,000$ project is being fully cost-shared by the private companies and government entities who are evalu- ating the effectiveness of multispectral and hyperspectral imaging technology. Never before has a large-scale scientific study with this technology been conducted on Montana weeds.

"Multi- and hyperspectral imaging can capture information well beyond what is visible with the naked eye," explained Dan Swanson, project coordinator and director of Agriculture Initiatives at the Montana State University-Bozeman (MSU) TechLink Center. "As such, they offer the promise of mapping weeds from airplanes and even from space. But can they deliver?"

To find out, crews headed out to the fields and airfields in August. The ground portion of the experiment involved six people mapping two, 4-square mile plots. One site was southwest of Twin Bridges in the Ruby Valley drainage. The other was located just west of the historic Virginia City in Madison County. With hand-held global positioning system (GPS) equipment and topographic maps, the two-person teams started by determining their locations on a grid map. Each foursquare mile area was divided into 16 blocks. The teams then 


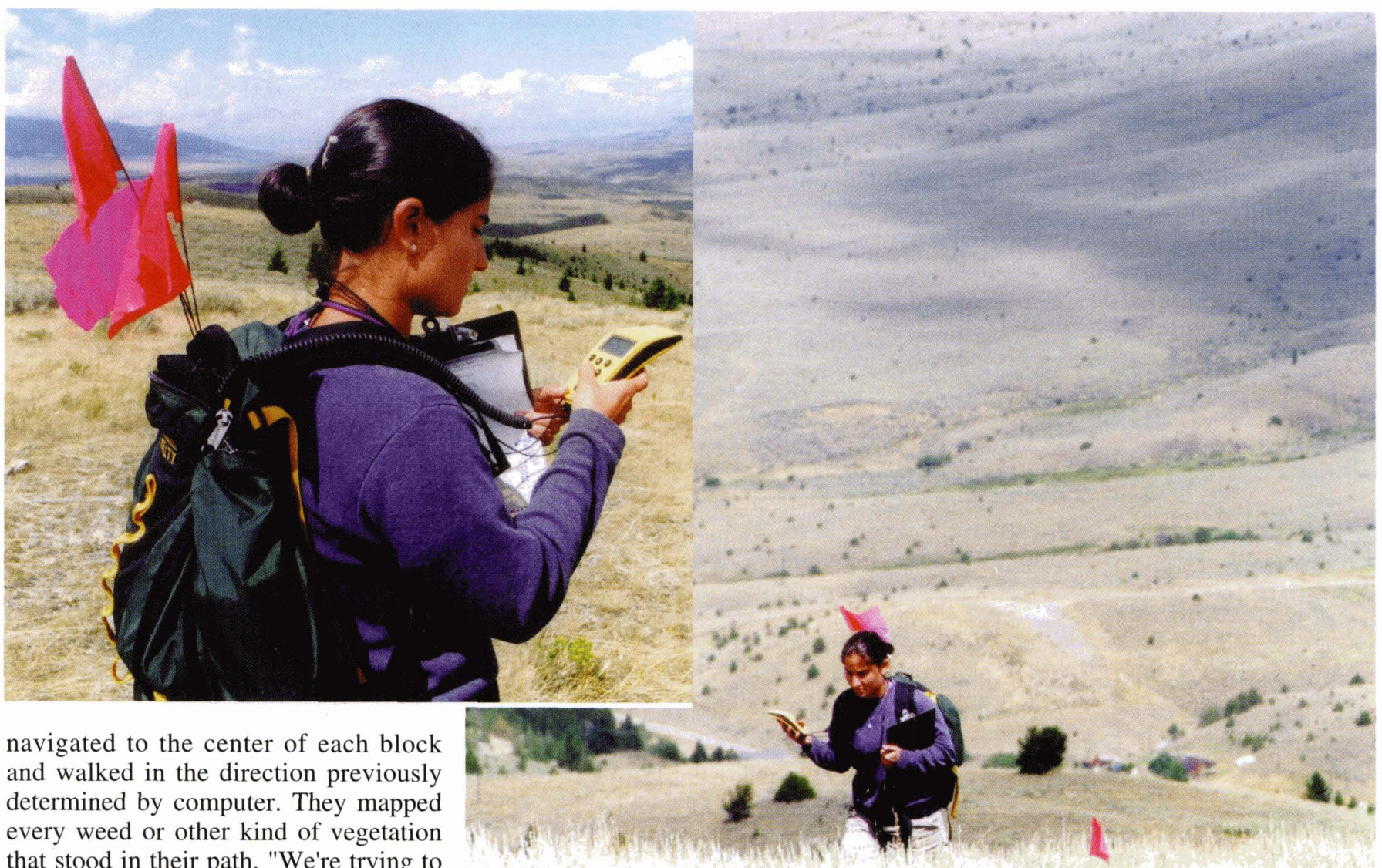

that stood in their path. "We're trying to get a random assessment of what's out there," said Elizabeth Roberts field project leader.

The above-ground information came from three companies using remote sensing equipment and one company taking video images. Flying in the same kind of airplanes used for aerial photography, these crews covered the identical plots the ground crew had hiked.

Hyperspectral Sciences, Inc. of Sonoma, Calif. flew first, using an Airborne Real-Time Imaging System (ARTIS) to capture multispectral images in three slices ranging from green through near-infrared. Each pixel represented about one foot. The ARTIS system is based on a multispectral camera developed by Kodak, and was developed by Hyperspectral Sciences for the NASA-Ames Research Center. In this project, GPS technology guided the airplane and also revealed the exact location every time the camera took a digital snapshot. The camera was linked to computers that told it how often and when to take pictures.

Next was Positive Systems of Whitefish, Mont. This company used the ADAR(tm) System 5500 to collect

multispectral images in four bands - the blue, green, red and near infrared. Each image covered about 1.5 square kilometers ( 370 acres) on the ground, with each pixel showing one square meter (about 1 square yard) of area. Similar to the ARTIS system, the ADAR System 5500 captured digital images through the belly of the plane. But instead of using a single camera with a color infrared filter. ADAR used four separate cameras that were individually filtered to record specific wavelengths in each spectral band. The cameras were synchronized via computer to also record a GPS position while controlling the exposure of the image and the firing of the shutter. "This system is frequently used in remote sensing applications requiring vegetation monitoring," said Bruce Burger, Positive Systems market development manager. Examples include precision agriculture, natural resource management and environmental compliance.

The third flight was by Earth Search Sciences, Inc. of McCall, Idaho. Using the Probe 1 system, this company col- lected hyperspectral images in the blue through medium-infrared range. Each pixel represents five meters (about 15 feet) on the ground. Light from the ground struck a mirror and split into 128 bands of the spectrum. "This level of spectral resolution provides details not only on the whereabouts of plants, but also differentiates among plant species" said Tim Monroe of Earth Search about the Probe l's capabilities. "We are going to look at each of these to evaluate their efficiency, accuracy and cost-efficiency," Rick Lawrence said of the three remote sensing approaches. Lawrence is one of two principal investigators for the weed experiment. $\mathrm{He}$ is also responsible for analyzing the information in his computer remote-sensing laboratory at MSU-Bozeman. "The most critical goal is to establish the statistical relationship between the noxious weeds detected from the air in a range of spectral bands, and the noxious weeds detected on the ground in the visible range," added a memo about the project.

Before Lawrence and his team can an- 


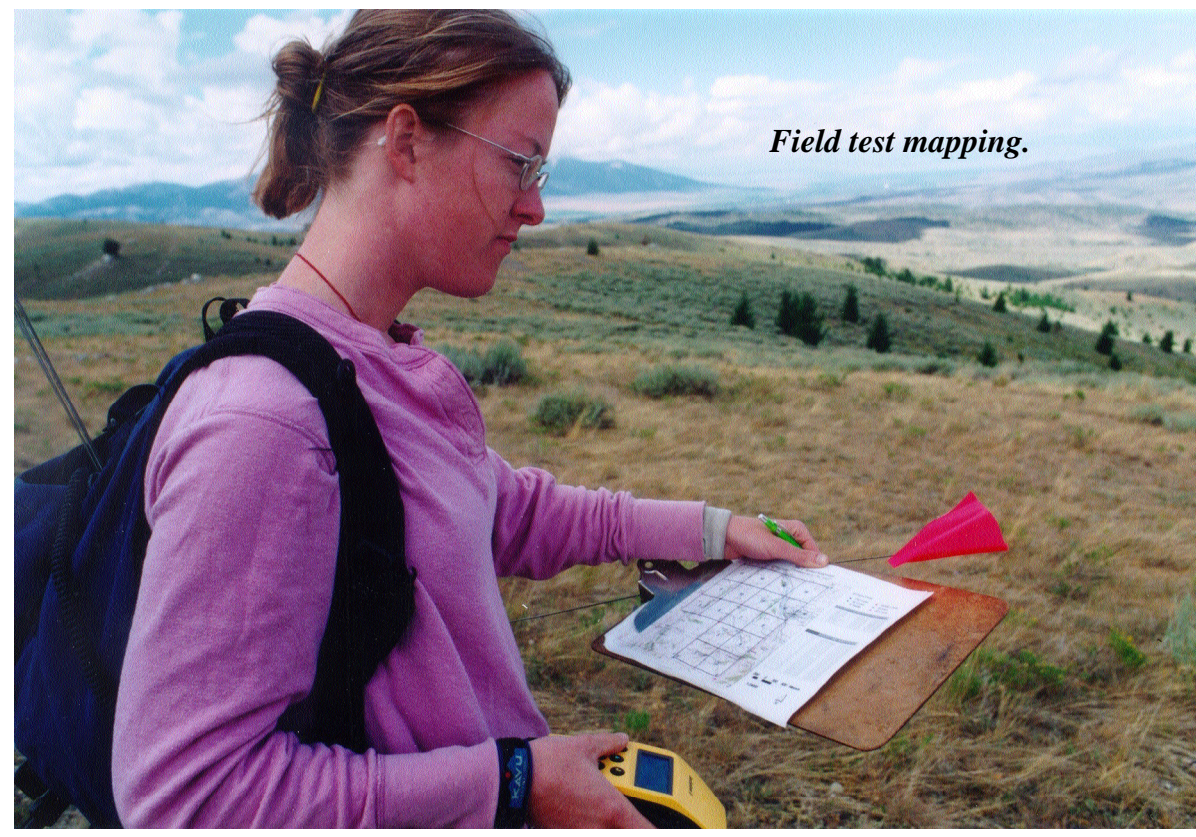

alyze the inormation, however, they must pre-process the images. That includes mosaicing multiple images into a single scene, correcting for camera distortion and geo-referencing the material. The analysts will then compare the maps made by the MSU ground teams with hyperspectral and multispectral images. These images will be supplemented by GPS-referenced video provided by Red Hen Systems of Fort Collins, Colorado and Precision Partners of Fargo, N.D.

Researchers will use two computer programs to examine the multispectral and hyperspectral data, Lawrence said. ERDAS Imagine will handle the multispectral data. ENVI will be used to analyze the hyperspectral data. Within those two programs, the MSU researchers will also develop their own algorithms for handling the information.

It could be a couple of years before the analysis is complete, but preliminary results may be available in the spring of 2000. Lawrence said, "It will take a long time to really know entirely how much we can push this imagery because we are trying new things."

Although remote sensing has been used in the past to detect spotted knapweed and leafy spurge, the current experiment is unique in many respects. Lawrence and his colleagues are developing training data from the imagery based on GPS sites. Collaborators believe that this has greater potential than previous approaches for making the technology operational because it relies on data that can be readi- es of weeds," Lawrence said. "We can compare and see. When do patches get so small that we can't accurately detect them any more? Do we have to wait until they bloom because they can have a different color?"

One problem with remote sensing is that "Vegetation is essentially all made up of the same stuff-like chlorophyll, lignin, but in varying proportions," Lawrence explained. "Therefore, vegetation tends to look very similar spectrally. Basically, it's green." Current methods for mapping and monitoring weeds, even with GPS, are also slow, expensive and do not offer economies of scale over large areas.

Participants in the experiment hope to overcome those traditional challenges and discover that remote sensing is a powerful ally in the war against noxious weeds. If the information can be gathered efficiently and provided commercially at an affordable rate, organizers say the experiment will be a success. "This is no trivial experiment. Noxious weeds are probably the No. 1 environmental threat in the West today," says Roger Sheley, the other principal investigator in the project. Sheley is an associate professor at MSU-Bozeman and noxious weeds specialist for MSU Extension. Leafy spurge and spotted knapweed are the two primary weed pests in Montana and the surrounding types of weeds, different sizes of patch- ly gathered over large areas and does not depend on ground spectro-radiometer prect is also comparing three han previous studies.

"This information will let us know how the accuracy of technology changes

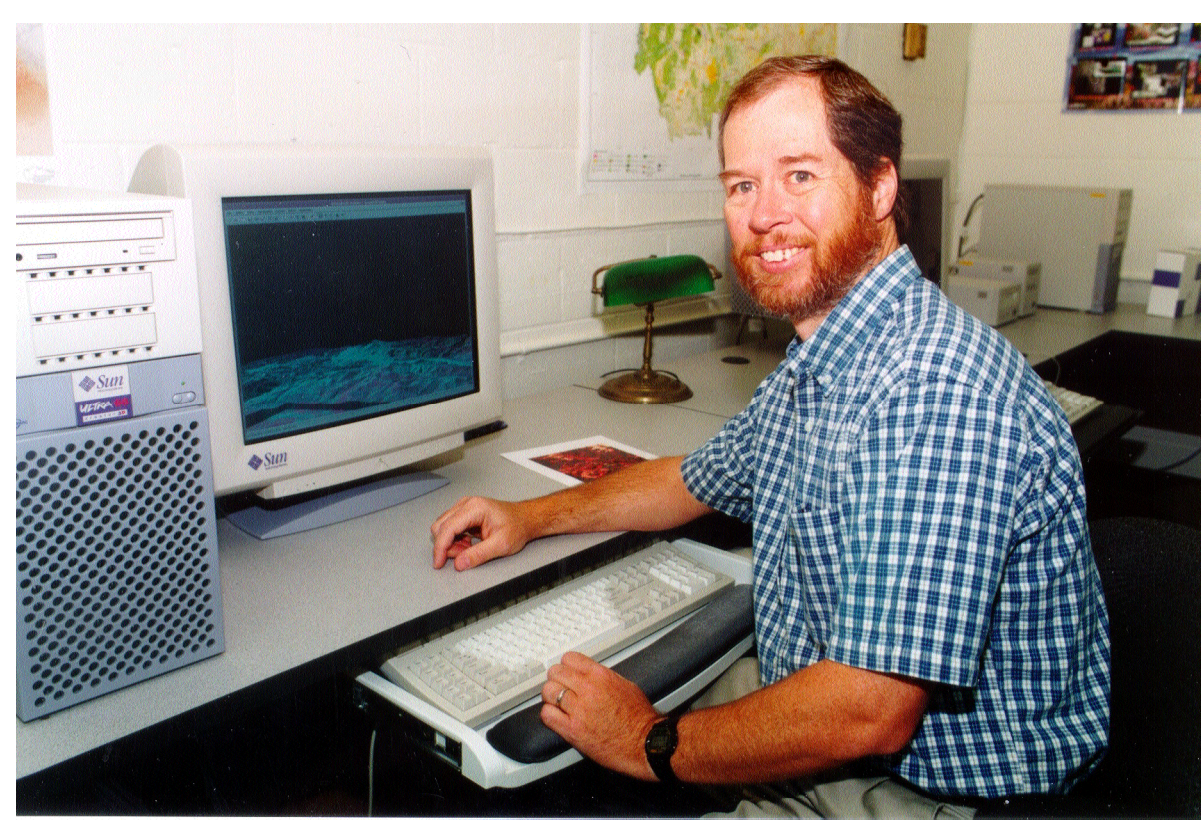

Dr. Lawrence at his computer 


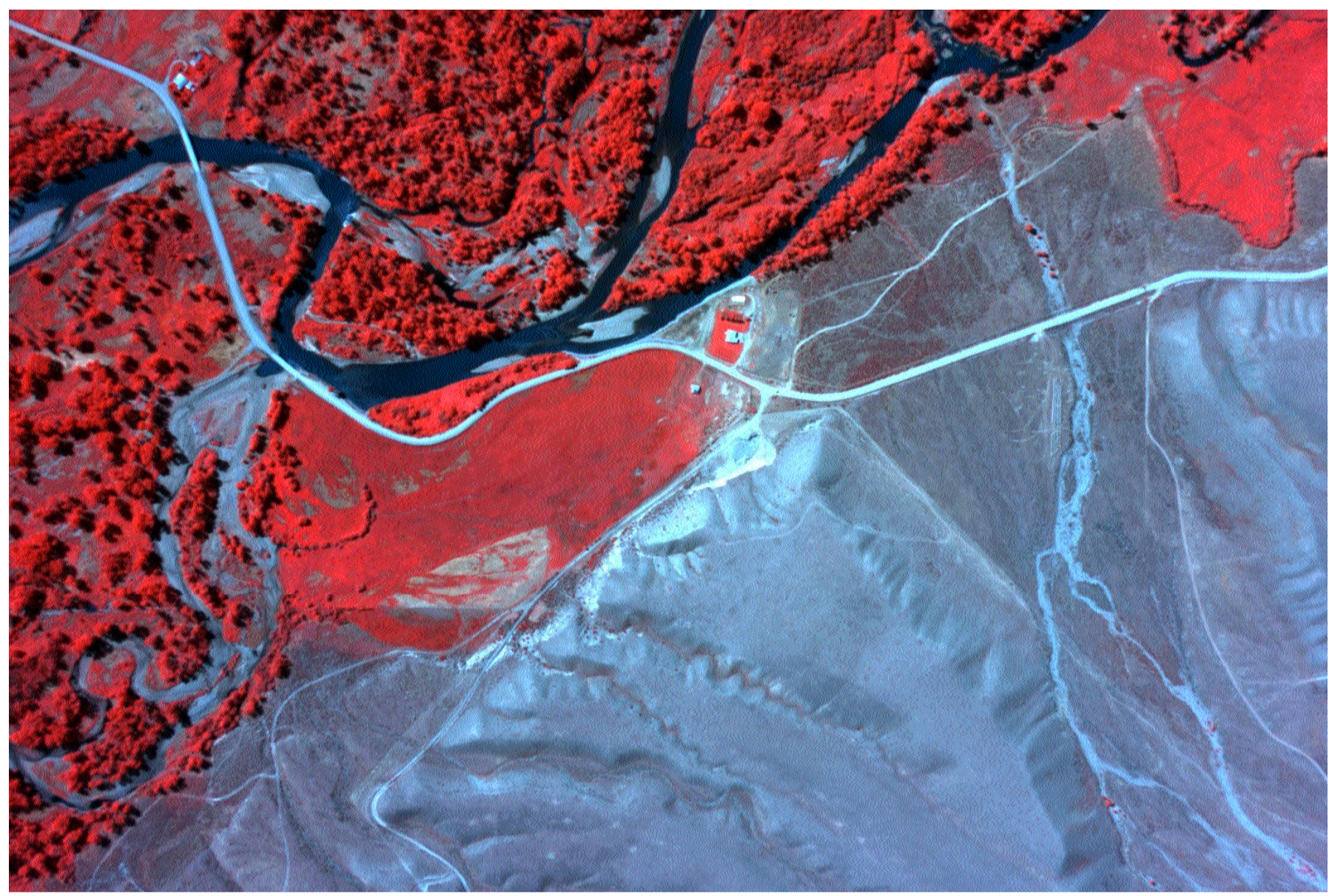

region. Leafy spurge infests at least 29 states and costs Monana, Wyoming and The Dakotas an estimated \$144 million every year. Spotted knapweed infests all of Montana's counties and is spreading rapidly. "Without understanding where these weeds are or where they fit across the landscape, it's impossible for us to develop strategy," Sheley said.

Dow AgroSciences is one company that's interested in this strategy. Dow became involved in the experiment because it has traditionally supplied weed and brush control products for pasture and rangeland, said Karl Schnelle who works in global ag math modeling and analysis at Dow. "With increased competition globally, the company is now trying to determine how to better support our products for the future," Schnelle said. "One way would be to have our technology development or sales force be able to easily identify weed locations, coverage and even species."

From global to local, collaborators on the project have high hopes. "This new tool will be unbelievably useful," said Kim Hudson who works for the Madison County Weed Board and supervises crews that spray weeds on Bureau of Land Management (BLM) property. Hudson currently relies on hikers and others who frequent the backcountry to let him know about weed infestations he hasn't discovered himself. "The noxious weed issue is one that we've been working on very diligently with land owners and land managers for a number of years," says Dave Schulz, weed coordinator for the Madison County Weed Board. "We haven't fixed the problem by any means, but I believe with vigilance and certainly a lot of hard work, this is one problem that we are going to beat."

The Montana weed mapping project was organized by the MSU TechLink Center, a technology transfer center funded by the National Aeronautics and Space Administration (NASA) and the Department of Defense. Other collaborators, besides those already mentioned, include Turner Enterprises, BLM and the U.S. Forest Service.

Evelyn Boswell is a writer in the Office of the Vice President for Research and Creative Activity at Montana State University-Bozeman. Before working at the university, she was a newspaper reporter in Montana and Iowa. She received a degree in journalism and politcal science from Iowa State University. 